\title{
Traumatismos maxilofaciais em mulheres vítimas de violência física: Revisão de
}

\section{literatura}

\author{
Maxillofacial injuries in women victims of physical violence: Literature review \\ Lesiones maxilofaciales en mujeres víctimas de violencia física: Revisión de literatura
}

Recebido: 20/07/2021 | Revisado: 25/07/2021 | Aceito: 26/07/2021 | Publicado: 02/08/2021

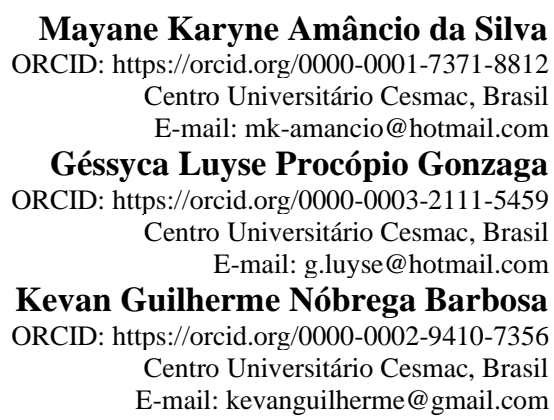

\begin{abstract}
Resumo
Objetivo: Descrever os traumas faciais em mulheres que são vítimas de violência e a atuação do Cirurgião- Dentista no atendimento desses casos. Métodos: Trata-se de um estudo de revisão narrativa da literatura sobre a temática traumatismos maxilofaciais em mulheres vítimas de violência física. Resultados: A região da face se torna um alvo pelo fato de o agressor poder visualizar claramente a sensação de dor, sendo uma forma de exteriorizar o domínio sobre a mulher, uma vez que muitas vezes seu desejo é depreciá-la e torná-la submissa. É possível utilizar parâmetros de que a cada 4 minutos uma mulher é agredida, sendo seus parceiros/companheiros caracterizados como os principais agressores $(65,6 \%)$, seguido dos ex-companheiros $(24,2 \%)$, conhecidos $(8,73 \%)$ ou desconhecidos $(1,47 \%)$. Dentre os traumatismos maxilofaciais decorrentes de violência contra a mulher, tem sido reportado que as injúrias em tecidos moles na face são as mais prevalentes. Conclusão: Conclui-se que os traumatismos maxilofaciais por violência em mulheres tem um número expansivo, com isso se faz preciso o reconhecimento do cirurgião dentista no cenário intervindo no combate à violência.
\end{abstract}

Palavras-chave: Violência contra a mulher; Cirurgião-dentista; Traumatismos Maxilofaciais.

\begin{abstract}
Objective: To describe facial trauma in women who are victims of violence and the role of the Dentist-Surgeon in treating these cases. Methods: This is a narrative review study of the literature on the subject of maxillofacial trauma in women victims of physical violence. Results: The face region becomes a target because the aggressor can clearly visualize the feeling of pain, being a way to externalize the dominance over the woman, since her desire is often to depreciate her and make her submissive. It is possible to use parameters that every 4 minutes a woman is attacked, with her partners/partners being characterized as the main aggressors (65.6\%), followed by ex-partners $(24.2 \%)$, acquaintances $(8.73 \%)$ or unknown $(1.47 \%)$. Among the maxillofacial injuries resulting from violence against women, it has been reported that injuries to soft tissue on the face are the most prevalent. Conclusion: It is concluded that maxillofacial trauma due to violence in women has an expansive number, thus it is necessary to recognize the dentist in the scenario intervening in the fight against violence.
\end{abstract}

Keywords: Violence against women; Dental surgeon; Maxillofacial trauma.

\section{Resumen}

Objetivo: Describir el trauma facial en mujeres víctimas de violencia y el rol del Odontólogo-Cirujano en el tratamiento de estos casos. Métodos: Se trata de un estudio de revisión narrativa de la literatura sobre el tema del trauma maxilofacial en mujeres víctimas de violencia física. Resultados: La región de la cara se convierte en un objetivo porque el agresor puede visualizar claramente la sensación de dolor, siendo una forma de exteriorizar la dominación sobre la mujer, ya que muchas veces su deseo es menospreciarla y hacerla sumisa. Es posible utilizar parámetros de que cada 4 minutos una mujer es agredida, caracterizándose sus parejas / parejas como los principales agresores $(65,6 \%)$, seguidas de ex parejas $(24,2 \%)$, conocidos $(8,73 \%)$ o desconocidos $(1,47 \%)$. Entre las lesiones maxilofaciales resultantes de la violencia contra la mujer, se ha informado que las lesiones en los tejidos blandos de la cara son las más prevalentes. Conclusión: Se concluye que el trauma maxilofacial por violencia en las mujeres tiene un número expansivo, por lo que es necesario reconocer al dentista en el escenario que interviene en la lucha contra la violência.

Palabras clave: Violencia contra la mujer; Cirujano dentista; Traumatismo maxilofacial. 


\section{Introdução}

Segundo a Declaração das Nações Unidas de 1993, a violência contra mulher inclui todo ato violento por razão de gênero, que produz ou pode causar dano físico, sexual, psicológico ou algum tipo de sofrimento diante de ameaças ou privações arbitrária de sua liberdade, independentemente se o ato ocorre de forma pública ou em algum local privado. Este fenômeno representa um problema social e de saúde pública complexo, que independe de fronteiras de classe social, raça, etnia, idade e grau de escolaridade (ONU, 1993). Entre os danos reais à saúde da vítima de violência, estão dificuldades ligadas à sexualidade, mutilações, complicações obstétricas e traumatismos maxilofaciais (Nascimento et al., 2012).

As agressões faciais tendem a ter um maior impacto por se tratar de áreas extremamente visíveis, tendo como alvo a região de cabeça e pescoço, das quais as sequelas físicas permanecem como cicatrizes, perdas dentárias e disfunções mastigatórias (Nascimento et al., 2012; Duarte, 2018 apud Vilela et al., 2019).

Uma agressão localizada na face não se limita apenas a lesões visíveis ou sem perda funcional, ela pode envolver além de tecido mole e ossos, a depender da extensão, o cérebro, olhos, seios maxilares e dentição (Roselino, et al., 2009).

Os traumatismos maxilofaciais causados por violência têm se mostrado em crescente ascensão (Dias, et al., 2014). Alguns aspectos sociais e relacionados ao ato violento interferem no acometimento dessas injúrias traumáticas à face da mulher agredida, como, por exemplo, o nível socioeconômico, a etnia, a escolaridade, uso de álcool e/ou outras drogas, o instrumento utilizado durante a agressão, entre outros. Agressões na face, local considerado de maior visibilidade humana, podem gerar sequelas físicas, como cicatrizes, perdas dentárias, disfunções mastigatórias, bem como sequelas emocionais que persistem como marcas ou lembretes dolorosos do abuso (Netto, et al., 2014).

No Brasil, as estatísticas referentes às agressões contra a mulher nos últimos anos apontam que $23 \%$ delas estão suscetíveis a sofrer algum tipo de agressão (Avarenga, et al., 2010). É possível utilizar parâmetros de que a cada 4 minutos uma mulher é agredida, sendo seus parceiros/companheiros caracterizados como os principais agressores (65,6\%), seguido dos ex-companheiros $(24,2 \%)$, conhecidos $(8,73 \%)$ ou desconhecidos (1,47\%) (Bernardino, et al., 2018). Em termos quantitativos, um estudo indicou que a maior parte das agressões ocorreram no interior dos domicílios (61,2\%), sendo marcadas por episódios repetitivos por se tratar de um ambiente familiar, restrito e privado, e decorrente dessa razão há menor probabilidade de interrupção de terceiros, sendo 52,2\% dessas agressões durante a noite (Leite, et al., 2014).

O traumatismo maxilofacial associado à essa violência, correspondente à quase metade dos casos, dificulta a conduta dos profissionais da saúde, uma vez que pode haver engajamento estético, comprometimento da autoestima e consequentemente gerando transtornos sociais (Netto et al., 2014). Pertinente às injúrias, as lesões estão associadas em traumas nos tecidos moles, traumatismos dentários e os de maiores expansões causam as fraturas ósseas (Marques et al., 2016). No que se refere aos traumatismos dentários, podem ocorrer lesões em tecidos duros bem como acometer a polpa dentária; alterações encontradas no esmalte, incluindo fratura de esmalte; fratura de esmalte e dentina sem exposição pulpar; fratura complicada de coroa; fratura de coroa e raiz sem complicações; fratura complicada de coroa e raiz e fratura de raiz (Castro, 2011). Nos tecidos periodontais, os traumas causam concussão, subluxação, luxação extrusiva, luxação intrusiva, luxação lateral e a avulsão, podendo esta ser a de maior comprometimento devido aos danos estéticos Referente aos tecidos ósseos, encontram-se as fraturas de parede alveolar, processo alveolar, mandíbula, maxila, processo zigomático e órbita (Chaves et al., 2018).

A presença da Odontologia, no que tange aos estudos de lesões do complexo bucomaxilofacial, torna-se indispensável tanto no diagnóstico quanto na tentativa de reparação dos danos. Isto porque, não é raro que a agressão física conduza à morte de milhares de pessoas como demonstram as informações dos diferentes Institutos Médico-Legais (Brasil, 2012).

A partir da identificação de um problema, um Cirurgião-Dentista precisa discernir a etiologia da afecção, como a forma da agressão e possíveis objetos utilizados, e por meio deste, obter melhor domínio sobre o tratamento e o prognóstico para cada caso. A Portaria $n^{\circ} 104$ do Ministério da Saúde expõe a obrigatoriedade da notificação compulsória, compreendendo 
a comunicação de casos novos de doenças e agravos, incluindo a violência (Garbin et al., 2014). A notificação compulsória é uma obrigatoriedade em território nacional imposta pela Lei n. ${ }^{\circ} 10.778 / 2003$, da qual possui o objetivo de intervir em casos em que a violência contra a mulher é identificada por meio de atendimento, visando o zelo pela dignidade e saúde da paciente, perante o inciso $\mathrm{V}$ do artigo $5^{\circ}$ do Código de Ética Odontológica, que permite a obtenção de dados numéricos a respeito da violência por meio de denúncias da vítima, testemunhas e profissionais da saúde, propiciando a elaboração de políticas públicas, a serem encaminhadas para as autoridades competentes. A notificação é efetivada de acordo com a classificação de lesões de natureza física, cabendo necessidade de procedência para as classificações graves ou gravíssimas (comprometimento definitivo da estética dentária e facial, comprometimento do sistema estomatognático por um período maior que um mês e demais complicações) (Silva, 2010; Carvalho et al., 2013; Silva, 2014).

Diante do exposto, o propósito do presente trabalho é realizar uma revisão de literatura sobre o traumatimo maxilofacial resultante da violência física, bem como destacar a atuação do Cirurgião-Dentista perante casos de violência.

\section{Metodologia}

Trata-se de um estudo de revisão narrativa da literatura sobre a temática traumatismos maxilofaciais em mulheres vítimas de violência física.

Como critério de inclusão, definiu-se publicações que tivessem como assunto principal traumatismo maxilofaciais e violência física, pela possibilidade de inclusão de um número maior de artigos. Além disso, incluíram-se publicações disponibilizados na íntegra na língua portuguesa e inglesa.

Para realizar este levantamento bibliográfico incluiu pesquisa em bases eletrônicas e busca manual de citações nas publicações inicialmente identificadas. Foram utilizados dados de 1993 a 2018. As bases eletrônicas pesquisadas foram literatura internacional em Ciências da Saúde (MEDLINE), Scientific Electronic Library Online (SciELO) e Biblioteca Virtual em Saúde do Ministério da Saúde (BVS). Foram utilizados descritores como violência física, Odontologia Legal e traumatismo maxilofaciais.

\section{Resultados e Discussão}

A violência de gênero é reconhecida como uma epidemia silenciosa, tornando a vítima ainda mais vulnerável e consequentemente podendo tornar perpétua a agressão como resposta ao seu silêncio. Essa situação é ainda mais comprometedora por soar de forma paradoxal a liberdade da vítima garantida pelos direitos humanos, uma vez que ela se sente coagida, com dificuldade de estabelecer novas fonte de relacionamentos, diálogo sucinto e restrito, elos de confianças vagos ou inexistentes (Carvalho et al., 2013).

A região da face se torna um alvo pelo fato de o agressor poder visualizar claramente a sensação de dor, sendo uma forma de exteriorizar o domínio sobre a mulher, uma vez que muitas vezes seu desejo é depreciá-la e torná-la submissa, segundo Nóbrega et al. (2017) e Silva et al.(2014).

Estudos evidenciam um maior número dos casos em mulheres com a faixa etária de 19 a 39 anos e tendo na maioria das ocorrências o companheiro ou ex companheiro como o principal agressor. Os estudos apontam também que entre $24,4 \%$ e 81,0\% dos traumatismos maxilofaciais em mulheres são causados por violência. As consequências mais relatadas entre as mulheres com traumatismos maxilofaciais por violência incluem problemas de auto percepção, de inter-relação social e de baixa autoestima. Os estudos ainda indicam também uma maior prevalência de lesões classificadas como leves na região maxilofacial e por esse motivo que o cirurgião-dentista é um agente importante para o reconhecimento e tratamento dos casos de violência (Chaves et al., 2018). 
Dentre os traumatismos maxilofaciais decorrentes de violência contra a mulher, tem sido reportado que as injúrias em tecidos moles na face são as mais prevalentes. Durante as agressões, a cabeça é uma região desprotegida, e a face é local de predileção do agressor devido ao que ela representa durante uma interação social; assim, a tentativa é provocar marcas para denegrir a autoimagem da vítima (Dourado et al., 2015). O tipo de trauma encontrado na maioria dos estudos foi em tecido mole, seguido por fraturas simples e, por último, trauma dentoalveolar. O predomínio de socos e chutes pode explicar esse padrão de lesão, uma vez que o padrão dos traumas depende fundamentalmente do agente, da força e da direção do impacto (Manganello, 2006 apud Chaves et al., 2018).

Dentre as formas de ataque, em $34,2 \%$ dos casos o ofensor faz uso de agressões nuas (socos, tapas, chutes e espancamentos), agressões penetrantes constituíram um percentual de 9,5\% de ocorrência (utilização de faca, armas, martelo, ou qualquer objeto perfurocortante), ou até mesmo a combinação de ambas (Dias et al., 2014).

Os tecidos moles são os mais atingidos, sendo a maioria no terço inferior ou médio da face (Bernardino et al., 2018). As lesões mais comuns são caracterizadas por erosão, hematoma, edema, ulcerações e lesões corto-contusas, seguidas por fraturas dentárias, podendo ser apresentadas isoladamente ou em combinação (Hage et al.,2014). Existindo também as alterações por traumas diretos, que foram registrados casos de laceração de frênulos labiais ou lingual decorrentes de violência sexual, pois o agressor tende a satisfazer seu prazer por meio do sexo oral e/ou outras práticas sexuais (Silva, 2010). Já nos tecidos periodontais, a afecção que apresenta maior percentual de ocorrências é a concussão, seguido da subluxação, luxação extrusiva, luxação intrusiva, e em menor ocorrência a avulsão (Chaves et al., 2018).

Nos tecidos ósseos as fraturas de maior incidência foram constituídas como as fraturas zigomáticas, fraturas orbitais e intracranianas (Oneida, 2009). Em contrapartida, as fraturas de parede alveolar, fraturas do processo alveolar em maxila ou mandíbula (fraturas do processo alveolar que podem envolver um ou mais dentes, deslocamento de bloco alveolar), fraturas de mandíbula (acomete região de côndilo, ramo e sínfise), fraturas de maxila (Le Fort I, II, III) também podem ser encontradas, além de sintomatologia dolorosa na região da ATM (Chaves et al., 2018).

A participação do Cirurgião-Dentista nos casos de violência é mais notável no IML, onde a partir do laudo de lesão corporal é feito a classificação das lesões. A lesão leve comumente não acarreta em grande dano à integridade corporal. Entretanto, outros tipos de lesões podem ser mais severas como em fraturas maxilomandibulares que impossibilitem o funcionamento habitual do sistema estomatognático por um período que ultrapasse um mês; fraturas radiculares ou coronorradiculares que ocasionem perdas dentárias; avulsão dentária; fraturas dentárias onde há perda da coroa; comprometimento definitivo da estética dentária quando a paciente sorri ou conversa; lesões de tecidos moles da face que comprometam significativamente a estética facial (cicatrizes, paralisia permanente dos músculos da expressão facial) (Garbin et al., 2015).

Sendo assim, a atuação do cirurgião-dentista se torna necessária durante os atendimentos clínicos diários das possíveis vítimas de violência, para identificar os fatores causais precocemente e notificar os casos suspeitos ao órgão especializado para a sua intervenção, e assim, oferecendo uma qualidade de vida a vítima.

\section{Conclusão}

Conclui-se que os traumatismos maxilofaciais por violência em mulheres tem um número expansivo, com isso se faz preciso o reconhecimento do cirurgião dentista no cenário intervindo no combate à violência. Os traumatismos maxilofaciais causados por agressão física contra mulheres ocasionam um grande impacto na vida social e psicológica, de forma a tornar a reinserção dessas mulheres no meio social difícil. Neste sentido, políticas públicas precisam ser construídas prioritariamente em ordem de diminuir o cenário de dor e descaso, sendo importante considerar a condição de fragilidade social sob quais estas mulheres se encontram. Havendo a necessidade da intervenção odontológica, o cirurgião-dentista deve se encontrar apto a 
detectar alterações que o induzam a identificação de agressões físicas. Essas situações requerem do profissional o conhecimento, sigilo e obediência à lei, a ser executada por meio da notificação compulsória, de acordo com o grau de lesões de natureza física, da qual permite não só a visualização desse fenômeno, como também a execução de medidas que venham a intervir, assim, zelando pela dignidade e saúde da vítima.

Recomenda-se que essa revisão possa contribuir na aplicabilidade de ações de prevenção da violência contra a mulher, promovendo ações de políticas públicas para diminuir a quantidade de agressões físicas e consequentemente traumatismos maxilofaciais.

\section{Referências}

Avarenga, A. M. et al. (2010). Etiologia e Incidência trauma faciais relacionado à violência doméstica à mulher. Revista do Laboratório de Estudo e Violência e Segurança. Marília, v. 5; n. 5; p. 118-125.

Bernardino, I. M. et al. (2018). Intimate partner violence against women, circumstances of aggressions and oral-maxillofacial traumas: A medical-legal and forensic approach. Legal medicine. Campina Grande, v. 31, n. 9, p. 1-6.

Brasil - Ministério da Saúde (2012). Norma técnica: Prevenção e tratamento dos agravos resultantes da violência sexual contra mulheres e adolescentes. 3a ed. Brasília: Secretaria de Políticas da Saúde.

Carvalho, L. M. F. et al (2013). O cirurgião-dentista frente à violência doméstica: conhecimento dos profissionais em âmbito público e privado. Revista Medicina. Ribeirão Preto, v.46, n.3, p.297-304, 2013.

Castro, T. L. (2011). Lesões Craniofaciais em mulheres vítimas de violência doméstica e familiar: registros do departamento médico legal de vitória (ES) entre 2004 e 2008. (Trabalho de conclusão de curso de mestrado em biologia bucodental com concentração em odontologia legal e deontologia), Piracicaba.

Chaves, A. S. et al. (2018). Prevalência de traumatismo maxilofaciais causados por agressão ou violência física em mulheres adultas e os fatores associados: uma revisão de literatura. Revista da Faculdade de Odontologia -UPF. Passo fundo, v. 23, n.1, p.60-67.

Dias, I. J. \& Santiago, B. M. (2014) Violência de gênero contra a mulher: perfil de registros periciais da Gerência Executiva de Medicina e Odontologia Legal (GEMOL) João Pessoa/PB. Rev Bras Ciên Saúde; 18(4):315-24.

Dourado, S. M. \& Noronha, C. V. (2015) Visible and invisible marks: facial injuries suffered by women as the result of acts of domestic violence. Ciên \& Saúde Coletiva; 20(9):2911-20.

Garbin, C. A. S. et al. (2015). Desafios do profissional da saúde na notificação da violência: Obrigatoriedade, efetivação e encaminhamento. Revista Ciência e Saúde Coletiva. Araçatuba, v. 20, n. 6, p.1879-1890.

Hage, C. A. et al. (2018). Traumas Faciais e morbidade bucal provocada pela violência em belém, estado do Pará, Brasil. Revista Pan-Amazônica de Saúde. Ananindeua, v.9, n.1, p. 41-49.

Leite, M. T. S. et al. (2014). Ocorrência de violência contra a mulher nos diferentes ciclos de vida. Revista Latino Americana de Enfermagem. 22(1):85-92.

Marques, R. C. et al. (2013). Oral and maxillofacial injuries in women: records of the medical legal institute of São Luís, maranhão, Brazil - from 2010 to 2013. Revista de Pesquisa da Saúde. São Luís, v. 17, n. 2, p. 69 - 73.

Nascimento, L. S., Hage C. A., Nakano, A. M. S., Azevedo, P. S. B. \& Lettiere, A. (2012). Violência contra à mulher e consequências à saúde bucal. Gênero na Amazônia; 2:149-56.

Netto, L. A., Moura, M. A. V., Queiroz, A. B. A., Tyrrell, M. A. R. \& Bravo, M. M. P. (2014). Violence against women and its consequences. Acta Paul Enferm; 27(5):458-64.

Nóbrega, L. M. et al. (2017) Pattern of oral-maxillofacial trauma from violence against women and its associated factors. Dental traumatology. Campina Grande, v. 33, n. 3, p. 181-188.

Oneida, A. (2009) Maxillofacial Injuries and Violence Against Women. Archives of facial plastic surgery. Pasadena, v. 11, n. 1, p. 48-52.

ONU - Organização Das Nações Unidas. (1993) Declaração sobre a eliminação da violência contra as mulheres. Proclamada pela Assembleia Geral das Nações Unidas na sua resolução 48/104.

Roselino, L. M. R., Bregagnolo, L. A., Pardinho, M. A. B. S., Chiaperini, A., Bérgamo, A. L., Santi, L. N. et al. (2009). Danos buco-maxilo-faciais em homens da região de Ribeirão Preto (SP) entre 1998 e 2002. Odontologia, Ciência e Saúde - Revista do Conselho Regional de Odontologia de Minas Gerais. 10:71-7.

Silva, C. J. P. et al. (2014) Traumatismo maxilofacias como marcadores da violência urbana. Revista Ciência e Saúde Coletiva. Belo Horizonte, v.19, n.1, p.127- 136 .

Silva, R. F. et al. (2010). Atuação Profissional do Cirurgião-dentista diante da Lei Maria da Penha. Revista Sul-Brasileira de Odontologia (ONLINE). Joinville, v.7, n.1, p.100-116. 